\title{
The Dynamics and Challenges of Interdisciplinary Collaboration: A Case Study of "Cortical Depth of Bench" in Group Proposal Writing
}

\author{
$-\mathrm{JOHN}$ C. GOOCH
}

\begin{abstract}
This study contributes to a discussion on collaboration and technical/professional communication in indeterminate zones or less familiar sites for collaboration. The interdisciplinary group for this case study collaborated to write a project proposal to solicit funds from the US government for constructing a test bed for immune buildings as a tactic for combating potential biological and chemical terrorist incidents. Their approach to collaboration coincided with several approaches previously addressed in professional and technical communication research. Novel and creative approaches emerged as a result of this collaboration, but in some instances, disciplinary differences, as manifested by disputes over concepts and terminologies, posed obstacles to collaboration. Such challenges necessitated strong leadership, which was also critical for managing group process.
\end{abstract}

Index Terms-Biological terrorism, chemical terrorism, corporate contexts, disciplinary perspective, group process, immune building, indeterminate zone, interdisciplinary collaboration, technical and professional communication, test bed.

\begin{abstract}
$\mathbf{F}$ or an interdisciplinary group to obtain federal funding for a project, effective collaboration becomes necessary for success. However, collaboration among individuals from different disciplines can bring about some unique challenges. The group for this case study in interdisciplinary collaboration came together to write a project proposal to fund a test bed for an immune building in an effort to combat biological and chemical terrorism. The interdisciplinary nature of this group sometimes created challenges for collaboration, but members also offered unique perspectives that contributed to the writing process.
\end{abstract}

The purpose of the current study lies in contributing to a discussion about collaboration and professional/technical communication by examining an interdisciplinary group. This study adds to the professional and technical communication scholarship in two ways. First, the study contributes to an ongoing discussion about collaboration and technical/professional discourses by examining a mostly noncorporate and entirely interdisciplinary collaborative situation. Second, the study focuses upon the challenges, conflicts, and tensions that emerge when experts from very different disciplines (architecture, engineering, mathematics, and science) negotiate content for a document. Furthermore, this study seeks to discover the more critical aspects and practices for successful interdisciplinary collaboration

\footnotetext{
Manuscript received March 18, 2004; revised June 10, 2004. The author is with the Department of Communication, School of Arts and Humanities, University of Texas at Dallas, Richardson, TX 75083 USA (email: jcgooch@vzavenue.net).
}

IEEE DOI 10.1109/TPC.2005.849646 by analyzing issues of leadership and group interaction. Scholarship currently addresses how groups of individuals who work collaboratively and who are part of different subfields-particularly in the sciences-collaborate; however, it becomes important to examine more completely how people who are not accustomed to working together may engage one another, especially in a more noncorporate setting. The descriptors of effectiveness for interdisciplinary situations, like the one for this study, are not well known.

Academic scholarship in professional and technical communication explains that certain key features and specific practices are necessary for effective collaborations. For example, previous research explores the importance of continuous dialogue among members as well as the most effective methods for revising drafts. Several studies address intradisciplinary as opposed to interdisciplinary group process, examining only specific disciplinary professionals as they work in mostly corporate contexts, while other studies address the professional writer's interactions and collaborations with subject matter experts (SMEs). By examining how different people from both different disciplines and organizations-some corporate and others noncorporate-work together, this study confirms some of the previous findings and raises questions about how experts work together in interdisciplinary groups. New knowledge emerging from this case study will ultimately enhance an understanding of interdisciplinary collaborative processes, subsequently leading to improving those processes. Improving interdisciplinary collaboration becomes 
even more crucial at a time when the federal government is continually asking for methods to address the terrorist threat that require approaches necessitating expertise from a collection of individuals who belong to different academic disciplines.

The following passages present an analysis of relevant themes for the current study: (1) communication and collaboration in the disciplines, (2) negotiating issues and addressing problems, (3) management of group process, (4) models of collaboration, (5) authorship, (6) time constraints and emphasis upon efficiency, and (7) professional communication and cross-functional teams.

\section{Communication and Collaboration IN THE DISCIPLINES}

Professional and technical communication scholarship addresses multiple collaborative situations ranging from professional and technical communicators in the workplace to classroom interactions and the teaching of writing. In addition, recent studies address experts in their organizational contexts. For example, Baake's work explores the use of metaphor in discourse among scientists at the Santa Fe Institute [1]. Scientists collaborate on a variety of projects including reports, proposals, book chapters, and scientific articles. However, other studies address in a somewhat limited way the interactions of people who belong to multiple academic disciplines and subdisciplines.

Qin et al. define the concept of interdisciplinary research, or IDR, as "the integration of disciplines within a research environment" [2, p. 894]. They indicate that the integration, "implied by several definitions mentioned above, consists of interactions among individual scientists, between individual scientists and their organizations, and among different disciplines involved in the research" [2, p. 894]. Their study reveals that "most collaboration occurred among scientists from the same department or discipline" [2, p. 913]. The current study can contribute to a dialogue related to the work of interdisciplinary collaborators, but more importantly, it can help describe how interdisciplinary collaboration specifically affects the writing process-not necessarily a focus of the Qin et al. study.

Disciplinary communication also remains a focus of professional and technical communication scholarship. Several rhetoric and professional communication scholars, for example, explain rhetoric's presence in the disciplines and that academics from all disciplines essentially engage a rhetorical process to establish themselves in their respective disciplines. Contributors to the anthology The Rhetoric of the Human Sciences: Language and Argument in Scholarship and Public Affairs argue extensively and compellingly regarding academic professionals' use of rhetoric [3]. These authors contend that the economist, the literary critic, the cultural anthropologist, as well as the mathematician and the psychologist must convince audiences of their position to advance not only their ideas but also their status in their respective discipline. As useful as these studies are to professional and technical communication, however, the scholarship does not address explicitly how academic professionals from different, sometimes vastly different, disciplines might engage one another to write a document.

Scholars categorize disciplinary rhetoric as the rhetoric of inquiry, which is the focus of The Rhetoric of the Human Sciences as well as other works including McDonald's Professional Academic Writing in the Humanities and Social Sciences. Her work challenges assumptions that academic discourse only generates new ideas; she argues that academic discourse arbitrates issues as well as creates knowledge:

If the disciplinary community is not only the source of ideas and problem solutions, but also the ultimate arbiter of their value then the more academics working on the same problem, the more opportunities for discovery and negotiation. Because of the influence of Continental Theory in the humanities and some social sciences-for example, Foucault's "What Is an Author?"-emphasis has shifted, recently, to the individual's lack of importance as the source of new ideas: individuals are seen not as standing apart from communities but as socialized within communities. This notion of the community's importance in generating ideas is consistent with many explorations here, as will be seen, but it is perhaps more important to stress the role of community as arbiter, rather than community as generator. If some kinds of disciplinary discourse are less distinguished than others by the kind of progress this model of science describes, then we must look partly to the processes by which academic discourse communities monitor and arbitrate the work of the community. [4, p. 30]

McDonald's words stress the importance of academic communities and collaborative discourse formation. The experts I chose for this study act as a community, but this study extends McDonald's work by explicitly presenting the collaborative group as both arbiter and generator of discourse and by analyzing the integration of several disciplines for a writing project.

\section{NEgOTIATING ISSUES AND Addressing Problems}

Collaborators can both negotiate issues and cooperate to establish goals and bring about solutions to problems [5], [6]. Professional writers socially negotiate text, which implies "that a number of 
positions are articulated, that areas of agreement and disagreement are located, and that the disagreements are arbitrated by means of some strategy or facilitation" [6, p. 486]. However, it becomes important to examine how collaborators negotiate and cooperate to set goals, to advance solutions to problems, and to define content for documents. Sides' work, for example, uses the Myers-Briggs Type Indicator (MBTI) to reveal how an individual's personality affects the collaborative writing process in that "individuals envision, research, and solve problems in different ways, using a variety of successful strategies" [7, p. 14]. Sometimes, joining people together in different ways creates controversy and impedes group productivity because they do not necessarily understand each others' perspectives, personalities, and attitudes [7]. Sides also concludes that the MBTI can be used to identify psychological preferences, "enabling individuals to understand how they function to themselves and in others" [7, p. 14]. This conclusion supports the argument that by understanding others' contributions better, collaborators can break down barriers to collaborative writing. He also contends that each person must be allowed to contribute his or her own unique skills and abilities to collaborative writing. Sides' study suggests that if each person understands others better, then he or she can more effectively negotiate, set goals, and solve problems because he or she can more fully comprehend each person's valuable contribution.

Malone argues that for groups to negotiate effectively, set goals, solve problems, and define content, members usually establish rules for governing behavior. She found that group norms frequently come into conflict with certain occurrences, which makes negotiation and consensus difficult to achieve. For example, she indicates that if a group norm "states that all decisions must be unanimous, [then] the group cannot function when real differences occur" [8, p. 110]. When group norms and problem solving strategies conflict, groups must be flexible within the context of collaboration. Group members learn to recognize when a certain norm does not necessarily coincide well with the solution needed for a particular problem, and group leaders should recognize when these situations arise and allow the group members to change their norms so that they may effectively address problems.

Malone's work represents one of the few studies analyzing the role of the leader in a collaborative writing situation. She concludes that the leader is most effective when he or she can recognize when the group members have established certain norms of behavior on their own that may be different from norms that person would establish for the group. If the leader can remain flexible with regard to the group's establishment of such norms and also when they wish to bend or break those norms to solve a problem, the leader will be much more effective [8]. The leader's ability to perceive such occurrences and act appropriately can enhance group process or block their efforts. Malone's claim resonates because it reveals that a group leader can play a decisive role in either facilitating group interaction or inhibiting group process. For the current study, the group leader played a dominant role in managing and facilitating the multiple disciplinary perspectives, making the leader's role very much worthy of attention.

\section{Management of Group Process}

The research emphasizes strategies and models for effectively managing the group process. Lunsford and Ede's widely cited text Singular Texts/Plural Authors: Perspectives on Collaborative Writing helps set the stage, particularly for the late twentieth century, for studying collaboration among workplace writers. Chapter 2 provides case studies of different professional writers (engineers, scientists, management personnel) in each of their respective settings as they prepare and write documents. They found that collaboration follows seven different organizational patterns.

(1) Team or group plans and outlines. Each member drafts a part. Team or group compiles the parts and revises the whole.

(2) Team or group plans and outlines. One member writes the entire draft. Team or group revises.

(3) One member plans and writes the draft. Group or team revises.

(4) One person plans and writes draft. This draft is submitted to one or more persons who revise the draft without consulting the writer of the first draft.

(5) Team or group plans and writes draft. This draft is submitted to one or more persons who revise the draft without consulting the writers of the first draft.

(6) One member assigns writing tasks. Each member carries out individual tasks. One member compiles the parts and revises the whole.

(7) One person dictates. Another person transcribes and revises.

Their research indicates that collaborators use such patterns frequently, with no one pattern prevailing over another with regard to frequency of use or preference [9]. The research also reveals that the participants had not named any one of these patterns, but they could readily recognize distinctions among these different approaches to collaboration. A finding from Ede and Lunsford's work reveals the necessity of a plan to collaborate effectively. Groups need a pre-established course of action to guide and to direct group process. The focus groups of their studies do share this characteristic; participants cite that a plan focuses the group in the early stages of 
collaboration. One challenge of the present study lies in determining whether or not the group members organize themselves according to the patterns identified in existing literature.

Rice and Huguley's findings concerning organization and management of process concur with those of Ede and Lunsford. They indicate that group members most often plan and outline with each member while he or she drafts his or her respective part of the document [10]. Then the team compiles and revises the document. However, these authors observe the management of process and the organization of group activities as they exist within organizations and among those who are usually from the same discipline [10]. Management issues and effective organization become more challenging when persons begin collaborating across organizational cultures and across disciplinary boundaries [6], [11], [12].

\section{MODELS OF COLLABORATION}

The development of models of collaboration coincides with issues of management of group process, and these models describe or attempt to describe the patterns group processes may follow. Several previous studies attempt to characterize, and with considerable success, the nature of collaborative writing through various models. One of the most widely cited studies is Killingsworth and Jones' research examining the dichotomy between division of labor and integrated teams. They explain that the division of labor model rests on strict distinctions within organizational hierarchies with regard to workers' job functions and duties. The people at the top of the hierarchy make decisions, and workers are expected to respect these decisions and also the rules established for an organization. For purposes of productivity, workers engage in assigned tasks and do not (supposedly) deviate from assigned tasks. On the other hand, the integrated teams approach creates a more democratic form of organization so that employees can participate in decision making processes and communicate directly with people at all levels of an organizational hierarchy. Ede and Lunsford's "hierarchical model" closely resembles the division of labor model in illustrating how writing can become "carefully, and often rigidly, structured, driven by highly specific goals, and carried out by people playing clearly defined and delimited roles" [13, p. 480]. The goals are often "designated by someone outside of and hierarchically superior to the immediate collaborative group or by a senior member or leader of the group" [13, p. 480].

Killingsworth and Jones conclude that many organizations follow a division of labor model when collaborating on writing projects. However, they note that the integrated teams model is becoming slightly more pervasive in organizations, and it allows for "integration of employees from various discourse communities, which will allow effective interchange and new opportunities for education and training" [14, p. 220]. The benefit cited in this conclusion is of particular interest for this study because the statement necessarily implies that bringing together persons from different disciplines can result in added value for writing projects. These statements suggest that the integrated teams model and interdisciplinary collaboration can go hand in hand.

Whereas the Killingsworth and Jones' analysis identifies models of collaboration on a more macro and organizational level, Mirel et al. identify three collaborative models that can be characterized as micro level and pertinent for smaller groups attempting to compose written documents. Mirel et al. identify three models for collaboration by adapting Morgan's general scheme for collaborations. The three structures, or models, of Morgan's scheme are the assembly line, the swap-meet, and the symphony [15].

The assembly line model assumes rigid distinctions between the different stages of creating written discourse; these stages include compiling initial content, writing, designing, and completing the final document [15]. The model becomes very sequential because writers must write first and designers design last, with the final document at the end. The swap-meet model assumes interdependence between writing and designing; however, the writers and designers work separately to compose their portions, then jointly review them before proceeding to remaining document sections. The authors provide a Venn Diagram that describes the symphony model of collaboration in which writing, content, and design are integrated, with writers and designers knowing each other's concerns so well that they write and design together, "blending verbal and visual concerns like sections of an orchestra” [15, p. 261].

They conclude that a "harmonizing of perspectives" results in the most effective collaboration, and to achieve a harmonizing of perspectives among participants, they should work toward symphony and swap-meet collaborations that "engender textual choices that are greater than the sum of the parts that writers and designers compose on their own [assembly line model]" [15, p. 284]. One question that Mirel et al. pose at the end of this study is, "what must writers and designers understand and assimilate about each other and their fields in order to work in symphony?" [15, p. 285]. With regard to interdisciplinary collaboration, this study can push this question a bit further by asking what each disciplinary professional can "understand and assimilate about each other and their fields in order to work in symphony." The collaborators must know, understand, and appreciate each other's contributions to work together successfully. Morgan's 
symphony and swap-meet models can illustrate the collaborative process not only among writers and designers but also among writers from different disciplinary backgrounds who sometimes express very different opinions that can influence the formation of written discourse. Morgan's study suggests that if groups can work together harmoniously, then participants are more likely to understand and to appreciate each other's contributions.

Other models of collaboration also assert that more dialogic, integrated, and democratic forms of collaboration are more valuable and effective than more autocratic, rigid, and nonintegrated collaborations among participants. Schrage's "shared minds" model of collaboration is also widely cited in the literature, and it coincides with the integrated teams and symphonic models identified in the previous scholarship. The shared minds model contains ingredients of mutual respect, tolerance, and trust as well as continuous communication among members [16].

\section{AUTHORSHIP}

Collaborators can sometimes find themselves in disputes over authorship and who should receive credit for writing the document. Ede and Lunsford raise questions concerning authorship in technical documents, questions which are also pursued by Rehling in her analysis of collaboration between workplace and academic writers [17]. Ede and Lunsford indicate that "authorship functions in multiple, complex, and often conflicting ways" [9, p. 101]. Rehling echoes these sentiments and argues that "anticipating the importance of social influences upon writing and collaboration in the workplace, newcomers [professional writers] sensitized to different ownership attitudes would be better prepared as employees to answer, both ethically and pragmatically, the question, "is it theirs, mine, or ours?" [17, p. 48]. The question of who can claim authorship of a text is contextually determined by the collaborative situation.

This question of authorship may take on a new dimension when considering how different disciplinary professionals work together. The literature does not fully explore how authorship issues become even more complicated when collaborators who belong to different organizations, as well as different areas of expertise, begin to work together to compose written documents. Within organizational settings, authorship can become increasingly problematic because supervisors may expect professional writers to act as transmitters for the supervisor. In other words, the supervisor may expect the writer to know as much as he or she does about a particular subject and be able to write for the supervisor. The professional writer may act as someone who merely writes a document for the supervisor as if the supervisor were the actual author:

On the one hand, managers may equate their supervisory role with authorial responsibility and expect that writers will act as an extension of themselves, acting for them in the full sense of authorship; thus, for example, they may expect writers in their group to know as much as they do about an organizational problem and fault them for errors or omissions on a draft that are almost inevitable, considering the lack of supervisory direction about the assignment and the writers' limited perspectives of the situation. [18, p. 101]

The assumptions made by a collaborator, particularly one who acts in a supervisory or leadership capacity, may create problems for effective collaboration between supervisor and employee. The supervisor's presumption that the writer knows as much about an issue and/or problem as the supervisor may create tension among a group that leads to ineffective collaboration. Sherry and Myers note that groups work best when no one member possesses the expertise of the group as a whole, and with regard to authorship, it also seems logical that the whole group, who writes or helps write an entire text, claims some authorship for an entire text [19].

\section{Time Constraints AND Emphasis UPON EFFICIENCY}

Collaborative groups do have several goals and objectives in common. The deadline, for example, becomes one of the more obvious concerns, and collaborators usually exhibit considerable sensitivity to time constraints. Failure to submit a proposal, documentation for a new technology, or a technical report on time can result in failure to receive funding for a project, a delay in release of new software or hardware, or increased costs to the organization. Furthermore, the writers can lose credibility with their intended audience, superiors, and fellow coworkers if they fail to provide a written document in a timely manner. Time is critical in organizational contexts because "there may be no other domain in which the relationship between time and communication is more central than in organizations" [20, p. 220]. Sensitivity to time drives a number of other considerations in group process, and within workplace contexts the deadline can become a major unifying force in collaboration [21].

\section{Professional Communication and Cross-Functional Teams}

Scholarship also explores the dynamics of the cross-functional team, which Bishop defines as a "team that brings together an array of specialists who jointly and simultaneously make design and manufacturing decisions" [22, p. 5]. She also states 
that "the decision-making and action-producing processes used by cross-functional teams act together to speed up the overall cycle time by reducing sequential knowledge transfer activities, reducing rework, improving the flow of communication, and increasing knowledge at lower levels of organization" [22, p. 5]. The immune building experts for this study potentially represented a kind of cross-functional team:

Cross-functional teams generally include, on average, five to seven individuals who come together to solve particular problems; an individual or groups of individuals identify internal or external problems facing the firm. Such problems, among many, may typically include new product development issues, questions of diversification, or quality control concerns. Individual cross-functional team members may come from technical or nontechnical segments of the firm. A typical cross-functional team may consist of managers and staff personnel with experience as engineers, marketing specialists, accountants, human resource specialists, manufacturing personnel, or even technical support specialists. These teams also frequently include representatives from top management who serve as financial, marketing, or engineering specialists. [23, p. 7]

Certainly, the cross-functional team includes people with diverse backgrounds who attempt to solve a problem and try to accomplish goals. The immune-building experts were no different in that regard. However, most technical and professional writing studies attempt to describe the technical or professional communicator's role in the cross-functional team without actually discussing how that team creates discourse. For example, the February/March 2000 issue of Technical Communication describes the technical communicator's role in initiating and establishing cross-functional teams as well as maintaining good communication among members. Marchwinski and Mandziuk's piece, "The technical communicator's role in initiating cross-functional teams," presents case studies in which the technical or professional communicator can act as a facilitator, of sorts, for cross-functional processes [24]. In addition, Wick echoes these sentiments in the November 2000 issue of Technical Communication when he argues that technical communicators can play a key role in cross-functional teams as knowledge managers [25]. Within corporate contexts, technical and professional writers usually work in a cross-disciplinary manner with professionals from software and hardware engineering, and this research tends to examine the interdisciplinary dynamics between technical writers and engineering professionals. The scholarship does address, however, how different members of the organization may participate in collaboration, but many of these professionals do not participate directly in the writing process.

How do we expand the scope of previous studies to address more thoroughly the issues of interdisciplinary collaboration among people from several areas of expertise? Thompson's 2001 literature review, which appears in the IEEE TRANSACTIONS ON PROFESSIONAL COMMUNICATION, calls for additional case studies and empirical research focusing on collaborators. Quoting D. A. Schon, she contends that researchers should "push their investigations further-into indeterminate zones of practice" or situations where practice is "not smooth because the practitioner has encountered an unfamiliar situation" [26, p. 169]. She also states that a "theory of general practices important for technical communication requires a description of the decision-making processes experienced practitioners use to increase their expertise" [26, p. 169]. Thompson argues for studying collaboration as it exists in rather nontraditional situations, or when experts "cannot rely on previously established routines" [26, p. 169]. The particular case study for this project does address Thompson's call for further research in collaboration because these experts worked with individuals who belonged to disciplines very different from their respective discipline. Therefore, the experts could not entirely rely upon their own disciplinary practices and beliefs to collaborate effectively.

Description of Case Study Group I was employed by The Institute of Environmental and Human Health (TIEHH, pronounced "tie") at Texas Tech University between 1997 and 2001. Established in May 1997, TIEHH had become part of both Texas Tech University and its sister institution, Texas Tech University Health Sciences Center. Texas Tech formed TIEHH as a research program to assess toxic chemical effects on both the environment and the health of human beings, and I worked as staff support for communication and outreach as well as a professional writer. While I was there, I became friends with one of the scientists, whom I will refer to as Neuroscientist. Neuroscientist was working as part of a group writing a project proposal to develop a test bed for an immune building.

In theory, an immune, or "smart," building is designed so that if a terrorist releases a biological or chemical agent, the building can contain and eventually destroy that agent before it can harm those inside the structure. The test bed that Neuroscientist and his colleagues proposed to construct required the use of simulants, or agents that share the same physical and molecular properties as deadly agents but pose no threat when released into the test bed structure. The operators of the test bed would first evaluate the effects and behaviors of simulants before evaluating the effects and behaviors of actual chemical and 
biological agents. Neuroscientist explained that his group would prepare a proposal and submit it to the Defense Advanced Research Projects Agency, or DARPA, an office under the auspices of the United States Department of Defense. The group included members of academic institutions, staff from a private laboratory, members of an architectural firm, and employees from a large corporation. All parties would make important contributions to the proposal and the subsequent project. Neuroscientist explained that they would construct this test bed for an immune building at Reese Technology Center, a decommissioned Air Force base in Lubbock,

Texas, that had been converted into a research and industrial park (TIEHH was also located at the Reese Technology Center). The group members planned to obtain an old aircraft hangar and they would use this hangar for two years while they conducted multiple tests for developing immune buildings. The group began writing a proposal to DARPA in late September 2000 in response to BAA-006A, a federal agency document known as a broad agency announcement, or BAA, that represented the request for proposal.

I chose to study this group because it was composed of people from the widest variety of disciplines. The case study group also provided an excellent example of an indeterminate zone for collaboration because almost none of the case study participants were accustomed to collaborating in this sort of situation.

Each member was employed by an organization that could contribute to the group's effort. This group was composed of an electrophysicist, a neuroscientist, two architects, a mathematician, a mechanical engineer, and a marketing/management specialist from the corporation participating in the project. A large national corporation participated in this effort so that it could provide technology for this facility, and it employed the corporate representatives, who included Corporate Mathematician, Corporate Engineer, and Corporate Marketing Representative. The project also required the talents of Chemist, who was employed by a laboratory in New Mexico. Last, Neuroscientist was a faculty member from TIEHH, and Electrophysicist represented a prominent laboratory in the eastern United States. The group had decided beforehand that Electrophysicist would act as the leader. Table I shows each of these group members and their affiliations.

Timetable for the Proposal Writing The group had agreed to meet on September 29, 2000, so that they could begin defining tasks and initiating the writing process. The group agreed that each member organization would write two to three pages describing their respective organization's capabilities. Tasks for writing the proposal required that other group members draft paragraphs and sections for the document, send additional information (including additional data, diagrams, charts, and graphs) to
TABLE I

Group members, affiliations, and role

\begin{tabular}{l|l|l}
\hline \multicolumn{1}{c|}{ Member } & \multicolumn{1}{c}{ Affiliation } & \multicolumn{1}{c}{ Role } \\
\hline Electrophysicist & $\begin{array}{l}\text { Laboratory } \\
\text { (Eastern U.S.) }\end{array}$ & $\begin{array}{l}\text { Group } \\
\text { Leader }\end{array}$ \\
\hline Neuroscientist & TIEHH & Member \\
\hline $\begin{array}{l}\text { Corporate } \\
\text { Engineer }\end{array}$ & National Corporation & Member \\
\hline $\begin{array}{l}\text { Corporate } \\
\text { Mathematician }\end{array}$ & National Corporation & Member \\
\hline $\begin{array}{l}\text { Corporate } \\
\text { Represeng }\end{array}$ & National Corporation & Member \\
\hline $\begin{array}{l}\text { Chemist } \\
\text { Architect }\end{array}$ & $\begin{array}{l}\text { Laboratory } \\
\text { (New Mexico) }\end{array}$ & Member \\
\hline
\end{tabular}

Electrophysicist (the leader), provide indications of possible technology developments (referred to by the group as "TDs") as a result of the test bed project, and review drafts after Electrophysicist compiled their text for the proposal.

During October of 2000, group members collaborated via email; they also received direction via email from Electrophysicist. During this month-long period, members wrote paragraphs and sections for different parts of the proposal. Electrophysicist instructed each member to submit text that explained what "issues we are trying to solve and the innovation we are bringing (sic)." Table II shows an overview of the timetable for generating the proposal.

TABLE II

Timeline for immune-building group's proposal writing (July-November 2000)

\begin{tabular}{l|l}
\hline Date & Action \\
\hline July 21 & $\begin{array}{l}\text { Neuroscientist visits Electrophysicist's } \\
\text { lab }\end{array}$ \\
\hline September 15 & $\begin{array}{l}\text { DARPA Issues BAA00-006A (Broad } \\
\text { Agency Announcement) }\end{array}$ \\
\hline September 29 & Initial Meeting, 10:00 a.m. - 5:00 p.m. \\
\hline October 2 & E-mail Interchange Begins \\
\hline October 3 & $\begin{array}{l}\text { Organizations Report Organizational } \\
\text { Capabilities to Electrophysicist }\end{array}$ \\
\hline October 6 & Paragraphs Due to Electrophysicist \\
\hline October 18 & $\begin{array}{l}\text { Technology Development (TD) Items } \\
\text { Due to Electrophysicist }\end{array}$ \\
\hline November 7 & Meeting/Teleconference \\
\hline November 9 & $\begin{array}{l}\text { Electrophysicist Issues Draft } \\
\text { Executive Summary to Members }\end{array}$ \\
\hline November 10 & $\begin{array}{l}\text { Electrophysicist and his lab complete } \\
\text { draft proposal }\end{array}$ \\
\hline November 20 & Final Proposal Submitted to DARPA \\
\hline
\end{tabular}


Methodology For this research, I observed group interactions during two meetings (September 29 and November 7, 2000). All members of the group participated in the September 29 meeting, except for Chemist. For this meeting, the group members were seated around a conference table in the conference room at TIEHH. I sat away from the table in a chair behind Electrophysicist so that I would not become an obtrusive presence. I could not videotape or tape record, so I took notes with pen and paper that I later transcribed. The November 7 meeting took place as a conference call and all members were present. I took detailed notes of this event consistent with my activities on September 29. In addition, I interviewed project members for their reactions and responses to working with others from disciplines different from their own.

Research Questions The present study poses the following questions:

(1) What role does the group leader perform in a collaborative and interdisciplinary situation?

(2) How do interdisciplinary groups negotiate disciplinary differences in composing the document?

(3) What do interdisciplinary groups share with other case study groups in the professional communication literature?

(4) Do interdisciplinary collaborative situations follow already established models for collaboration?

(5) Do questions of authorship present themselves in an interdisciplinary situation for collaboration?

\section{Role of The Group LeAder}

Previous studies reveal the importance of effective management of group process, which necessarily relies upon effective leadership. Therefore, a question posed by this study asks what role the group leader played in this interdisciplinary group. Neuroscientist had informed me that prior to their initial September 29 meeting, the immune-building experts had decided that Electrophysicist would lead the group. According to Neuroscientist, the group members met briefly in late August or early September 2000 to discuss the project. Electrophysicist had asked the other members, "Who wants to lead us?" When no one responded, he said, "Well, I guess I'll do it" [27]. Neuroscientist suggested that it was Electrophysicist's way of asserting himself without brazenly assuming this role. It was explained to me that Electrophysicist did not wish to claim the leadership role overtly; rather, he wanted to take a "backdoor" approach by first asking the group who they wanted to lead them in the process [27]. When no one volunteered for the job, Electrophysicist seized the opportunity to name himself in charge. According to Neuroscientist, no one openly objected to his assuming the leadership role. Neuroscientist said that Electrophysicist, who belonged to an elite group of scientists working for an applied physics lab at a major university, had gained the most experience working with federally funded projects. Furthermore, he was more familiar than other group members with the bureaucratic complexities of the Department of Defense.

The leader performed several functions for the group including manager, contributing writer, and editor. Electrophysicist also established structure for the September 29 meeting, which became an important centralizing force for group process. For example, he took the initiative in writing down proposal issues and topics on the back of a napkin while traveling on an airplane between his home office and Lubbock. Furthermore, he asked each group member to make a presentation stating the capabilities and contributions his or her organization or division within that organization could make to the overall effort. Neuroscientist made the first presentation, stating that TIEHH could contribute the resources of location, research assistants for the project, and any needed laboratory facilities. TIEHH boasted at least twelve different laboratories containing significant technological and scientific tools for studying toxicological effects on both the environment and human health. The corporate representatives said they could provide products for the immune building and test bed, including filters and instrumentation for evaluating the toxicity of a particular substance. Architect said his firm could provide important consultation on design issues, and more than once, Architect reminded the group that his firm had gained considerable expertise in building high containment laboratories and facilities located all over the globe.

In establishing the structure for the group, Electrophysicist reminded the members of "system functionality." He argued that the group members must function like an efficient system to accomplish their goals, but he did not clarify what he meant by "systems approach" or "system functionality." Electrophysicist's use of the term "system" became important because it provided a metaphor for how he thought the group should be organized. It gave him a way to describe his thoughts on their structure and organization; he also played a major part in devising a plan, which is a common approach to collaborative situations [9]. If all the group members shared the systems perspective, then they would become more focused on the task. The use of the term implied that each person, and each component, would work together and perform individual tasks to bring about a cohesive document.

Electrophysicist also constantly requested "specification sheets and additional information," and his insistence upon such information suggested that the more information the group gathered, the more likely they were to write a valid document-at 
least in the eyes of their reviewers. He argued that the group, as a system, should consider issues of "asset management," "component research," and "[identification of] controls." Each of these terms metaphorically described the group's activities because each term described a specific task for the group. Rather easily, one could turn these nominalizations into verb phrases to signify action: manage assets, research components, and identify controls. These phrases depicted the initial actions Electrophysicist saw the group undertaking to complete the project. Assets would include their resources (technological solutions, laboratory capabilities, and human resources); components would include instrumentation and devices for the test bed; controls would include tests and measures for determining the effectiveness of the instrumentation. In Electrophysicist's mind, each of these operations would contribute to the group working together as a system. The systems metaphor helped the group members understand their tasks and the relationships among the different aspects of the project. Electrophysicist was most likely the best person to provide this scheme; he had previously told me that he had worked with such groups before, and for other members, this situation existed as an unfamiliar site for collaboration.

Electrophysicist's actions, particularly at the beginning of the process, helped focus the group members on the writing task, and the leader contributed significantly to this group's success. Several times during meetings he reminded the group to "get away from the theology," meaning that they should avoid straying into theoretical discussions that may only tangentially pertain or may not pertain at all to the document itself. Ultimately, his ability to manage a multiplicity of different disciplinary perspectives helped the group negotiate content for the document.

\section{Negotiating Concepts and Terms in A DISCIPLINARY MILIEU}

A second research question for the current study asks how interdisciplinary groups negotiate disciplinary differences to compose a document, and the following sections present observations of group process and analysis of that process to help answer this question. By virtue of their composition, interdisciplinary groups contain diverse talents and may bring dimensions to writing projects that more homogenous groups do not. However, disciplinary difference can represent a double-edged sword particularly if disagreements over concepts and terminologies emerge and become obstacles that the group must overcome to complete the writing task. The following sections explore how the group negotiated disciplinary difference and built consensus related to concepts and terminology. The following passages also report expert attitudes and how these attitudes necessarily characterize effective interdisciplinary collaboration.

\section{Milieu of DisciplinaRy Perspectives}

Achieving consensus with regard to concepts and terminologies became important for the immune-building group because such discussions directly affected the proposal's content. For example, Electrophysicist stated several times during the meeting that dose was the most important criterion for determining the effects of biological and chemical agents. Corporate Engineer, however, contended that "dose is important when discussing human beings, but not necessarily when discussing the environment in which the agent is released." Corporate Engineer said they should consider using concentration because this term would force the group to consider both human and nonhuman elements in constructing a test bed. A diversity of opinions about concepts, terms, and solutions began to appear as a milieu of sometimes competing disciplinary perspectives.

Efforts to resolve conceptual differences spoke to larger issues associated with disciplinary perspective. Each individual brought with him or her a particular disciplinary perspective, which sometimes became a disciplinary bias. These perspectives were sometimes manifested in disputes over terminologies or names for categories; however, deliberations over concepts and terminologies were in and of themselves part of a larger issue. Different disciplines practice different approaches to problem solving because each discipline prioritizes issues differently. Dose represents a term commonly used among scientists when studying a toxicological or chemical substance's effect on a human being or other animal species. In this instance, Corporate Engineer, who was more accustomed to working with nonhuman and inanimate objects, argued in favor of concentration to account for both human health and structural factors.

Although it discusses the importance of negotiation and consensus in collaboration, the professional and technical communication scholarship does not devote as much attention to how groups resolve such differences, especially differences related to concepts and terms. However, Bowker identifies a process of naming as part of conceptualization as a key issue for collaborating across disciplinary boundaries. Bowker explains the dynamics of scientists from different subdisciplines as they attempt to create a unified picture of global biodiversity, and he describes the problems of naming as part interdisciplinary communication. Bowker indicates that "one can have consistent sets of names in subdisciplines but no good way to bring them all (literally) onto the same map" [28, p. 16]. Moreover, it is problematic for one disciplinary community to integrate their "data" with that of a discourse community from a 
different scientific subdiscipline. The problem of integrating one subdiscipline of science with another becomes increasingly magnified when we discuss working across academic disciplinary boundaries. An engineer's perspective on how to describe a particular situation, characterize a problem, or identify a concept may differ significantly from a scientist's perspective about the same issue. A process of conceptual framing for the immune building group was possibly even more complicated than the process Bowker describes. The immune building collaborators represented not only different scientific subdisciplines but also different disciplines and perhaps subdisciplines as well. The dynamics Bowker outlines become even more complex when examining such situations.

Conflict, consensus, and resolution are inextricably intertwined in collaboration, and how these elements emerge can tell us much about the formation of a particular group [21]. When experts communicate, they communicate using a language specific to their discipline. Engeström and Miettinen explain that other individuals from outside the person's disciplinary community cannot readily understand this language because they do not possess the vocabulary or the sophisticated theoretical understanding of a person who has received this specialized training:

To put it simply, expertise in any given field is an ongoing dialogue or polyphony of multiple competing and complementary viewpoints and their respective "instrumentalities," repertoires of mediational means. The various voices represent "social languages" rooted in different societal positions, ideologies, and traditions of practice. The multivoicedness is both a resource for collective achievement and a potential source of fragmentation and conflict. [29, p. 9]

This condition existed for the immune-building collaborators because this group, composed of experts from a number of different disciplines (sciences, engineering, architecture), completed writing tasks amidst a milieu of sometimes competing perspectives and different disciplinary practices and biases.

This disciplinary milieu created a need for the group to begin building a common LEXIS. Eggins and Martin state that the "technicality of lexis" characterizes discourse; the literature on multidisciplinary interactions states that groups must build common "symbolic repertoires" [30], [31]. Swales also claims that developing lexis is a necessary condition for a group that becomes a (discourse) community:

This specialization may involve using lexical items known to the wider speech communities in special and technical ways, as in information technology discourse communities, or using highly technical terminology as in medical communities ... It is hard to conceive, at least in the contemporary English-speaking world, of a group of well-established members of a discourse community communicating among themselves on topics relevant to the goals of the community and not using lexical items puzzling to outsiders. It is hard to imagine attending perchance the convention of some group of which one is an outsider and understanding every word. If it were to happen-as might occur in the inaugural meeting of some quite new grouping - then that grouping would not yet constitute a discourse community. [32]

Swales' argument suggests that a group cannot become a (discourse) community until they have settled upon a common lexis that binds them together. Moreover, his argument implies that developing lexis is critical to group formation. For the immune-building group, the difference of terms or concepts (concentration and dose) revealed a difference between science and architecture as disciplines. Such deliberations pushed the group closer to writing a better document and also toward creating the best possible physical structure. Myers states that agreeing upon use of terms and concepts becomes a critical part achieving consensus in collaboration:

In the latest version of the proposal, Bloch makes another significant change in terms; for almost every occurrence of the word homologies, the central term of his project, he substitutes matching sequences or some equivalent. As we shall see in studying his articles, he stumbled onto the problem, common in interdisciplinary work, of a term that has a more restricted meaning in one field than in another. In molecular biology, as the reviewer's usage quoted in the previous paragraph shows, the word indicates any structural similarity. In evolutionary biology, the word can indicate only those structural similarities that result from common origins. If Bloch used the word in this sense while trying to prove common origins, he would be begging the question. But precision is not all that is at issue here; the change is part of the consensus-making process of proposal-writing. To use the word in the more restricted sense it has in evolutionary biology rather than in the broader sense it has in molecular biology is to acknowledge, or assert, that one's work will fit into both disciplines. [33, pp. 51-52]

In attempting to gain consensus, Corporate Engineer used a word that helped create compromise between the scientific perspective and the engineering perspective because the term concentration encouraged the group to consider both animate and inanimate objects. Corporate Engineer contributed to defining the document's content by contending that concentration should become a more important measure for determining the test bed's effectiveness. Furthermore, concentration accommodated both 
the engineer's perspective and the point of view of the scientists because the concept allowed them to conceptualize a deadly agent's effect on both human beings and inanimate objects. Consensus building helped mediate the final written discourse; however, not all disagreements associated with different disciplinary perspectives were as easily resolved.

\section{InCREASed Conflict Amidst the MiLIEU}

Corporate Engineer continually returned to his ideas on technological controls and products, specifically filters to neutralize agents. Architect insisted upon the containment idea and argued that containable space should "be held in high regard-they must determine what happens to the material in the room." However, Electrophysicist continued to urge the others to "get away" from the "theology" of the test bed and immune building; he pushed the group toward writing the statement of work, which would serve as one section of the proposal containing the "plan of action" or a detailed description of how the project would be implemented. Architect, however, did not acquiesce to Electrophysicist's desire to halt the containment discussion. Architect challenged Electrophysicist on the importance of the heating, ventilation, and air conditioning (HVAC) factor by arguing that HVAC was the most important consideration; however, Electrophysicist responded by saying, "the HVAC system isn't everything." This remark elicited a somewhat emotional reaction from Architect who exclaimed, "The HVAC system is everything!" Architect, however, offered no alternative to filters as a means for trapping biological/chemical agent particles. Electrophysicist returned to the idea that the HVAC system would remain only one component of the entire system. Electrophysicist said they should consider all the parts of the bigger whole, but Architect continued to assert the point that an immune building would rely heavily upon the HVAC system because it would transport agent particles.

Corporate Engineer interjected that "filters are a primary mechanism for decontamination," or a means by which to eliminate an agent's presence from a particular space. Architect contradicted this assessment, indicating, "filters are small, cheap, and largely ineffective." He stated that using containment served as a better approach because it forced the group to consider manipulating the physical space to isolate contaminants. Electrophysicist disagreed with Architect at this point, arguing that "filters are an important part of any decontamination system," but "they need to make certain that filters are reliable and effective." Electrophysicist indicated that tests "were imperative," and he reasserted the need for good data and "numbers."

Cross' most recent work, Forming the Collective Mind, describes this milieu of competing perspectives and the conflicts that surface for a milieu of perspectives by explaining that a "cacophonous outcome" emerges due to the diverse numbers of people who hold different job functions and/or who are members of different companies [34, p. 73-74]. This problem becomes magnified in interdisciplinary situations when people from vastly divergent disciplinary backgrounds participate in a writing project. Collaborators engage in planning and drafting from within their own disciplinary bailiwick and biases, which creates a unique challenge for collaboration. Cross argues that highly heterogeneous groups "are less effective than homogeneous ones; furthermore, a diversity of participants in collaboration can potentially hinder the forming of a collective mind," a concept I expand upon later in this piece [34, p. 74].

I observed three distinct differences in perspective among the subjects that can more accurately characterize this particular cacophony. Corporate Engineer, who happened to specialize in mechanical engineering, not only supported the technological solution to "decontamination," but he also argued in favor of one of his company's products-filters. Architect argued for a more "structural" solution; as an architect, he contended that using the test bed and immune building's space effectively was a more adequate method to "contain" agents. He reasoned that manipulating and organizing space was the best approach, but he provided no other alternative to the use of filters. Electrophysicist, as a scientist, represented a third perspective that pushed for tests, data, and more importantly, reliable data. Traditionally, a scientist hypothesizes over a given set of circumstances, or challenges widely held paradigmatic beliefs regarding those circumstances, relentlessly tests the hypothesis, and demands purity of fact for determining truth. Electrophysicist fulfilled this expectation because his remarks in the meeting consistently supported the need for facts, data, and good tests. Architect's concerns, however, were not completely addressed during the September 29 meeting. I later learned that filtration would remain the proposed technique contained on the pages of the final proposal document.

Debates over terminology and concepts remained unresolved at the close of the September 29 meeting. During the November 7, 2000 meeting, the issue of filters for the immune building once again became a point of contention when Architect labeled hepafilters, a specialized filter made to neutralize dangerous contaminants, an "off the wall idea." A member of the group, Chemist, who was not present for the September 29 meeting, stated that the group needed a "new filter approach." He believed that the filter approach for neutralizing contaminants would help provide the group with the means to "set themselves apart," a point with which Electrophysicist agreed. The group argued over various approaches including 
carbon hepafilters, filters, and fans. However, Architect continued to hold firm to his questions and concerns about addressing the space issue, and he argued that the proposal should emphasize the spatial arrangement of the structure and how the HVAC system would blow simulants in a particular direction. He believed that the immune building could contain the biological or chemical agent, quarantining it from the rest of the structure.

Differences in disciplinary perspective made defining terms and concepts more difficult. Each person had gained a number of years of experience in his or her respective discipline; with regard to this particular example, they were unwilling, at least in some instances, to abandon their particular perspective. Ultimately, the group decided to use filters because it was the best method for trapping substance particles. Both the scientists and the corporate representatives held firm in their support of filtration. In theory, the building would trap the substance with filters and then a furnace would burn and destroy the agent. Despite being outvoted, it did not prevent Architect from expressing his dissatisfaction, even late in the process. His opposition to filters can be attributed, at least to some extent, to a reluctance to look at the situation outside his own disciplinary position.

\section{EXPeRTS' AtTitudes Regarding the Milieu}

The immune-building group offers one example of new needs for collaboration. More importantly, situations like the one for the present study require that disciplinary experts learn new ways of communicating with persons in other disciplines, which suggests that for a collaborative process to become productive, participants should consider other experts' points of view and accommodate those points of view as well as engage new knowledge from other academic disciplines. Interdisciplinary collaboration requires that experts make connections between their disciplinary knowledge bases and new knowledge from other disciplines to collaborate effectively. Their ability to make such connections becomes even more critical when considering that interdisciplinary groups defining solutions for biological and chemical terrorist threats address issues with life and death implications.

During an interview, Neuroscientist metaphorically described the collaborative process between persons from different disciplines as "cortical depth of bench." I asked him exactly what he meant, and he said, "It [collaboration among different persons from different disciplines] is advantageous because you have more brains to draw upon. The number of neurons firing increases. No two people see the problem alike; it's like having a multi-faceted cube" [27]. Similarly, Weick and Roberts explain this condition as "heedful interrelating" as part of a collective mind in organizations [35, p. 357]. Like other collaborators, the immune building group members understood their roles within the group and engaged others in the group according to their roles. The group usually operated much like a living organism or "collective mind" [35, p. 357].

However, a greater number of neurons firing can also result in a greater chance for unsuccessful collaboration. Electrophysicist told me that "many heads may be better than one," but "too many cooks in the kitchen spoil the stew" [36]. He said, "Collaboration is like a team sport. When you have a team, someone is not going to give you excellence-not everyone will score a touchdown" [36]. Neuroscientist articulated a similar concern over too many persons in the process, and he explained that "committees can kill entire projects" because the collaborative writing process can take considerable time, especially when trying to achieve consensus among members [27].

\section{TOWARD A THEORY OF INTERDISCIPLINARY Collaboration and Professional COMMUNICATION}

The remaining questions for this study ask what interdisciplinary groups share in common with other collaborative groups as well as whether or not authorship concerns surface during interdisciplinary collaboration. While conducting this research, I also wanted to know if the immune-building collaboration conformed to previously established models and theories of collaboration and professional/technical communication. The remaining passages address these questions and also begin providing a basis for a theory of interdisciplinary collaboration and professional/technical communication.

The immune-building group shared similarities with other case study groups because the members knew they must effectively plan and manage the process as well as meet the deadline, which helped focus the group so that they could efficiently and effectively complete the writing task. The group also worked to negotiate issues and address problems; however, negotiating issues and addressing problems became more complicated because of the diverse composition. The diverse perspectives of interdisciplinary collaborators add a dimension of complexity to collaboration, which is already a complicated endeavor.

The immune-building group manifested characteristics of the swap-meet model and the shared minds model, both of which I have described earlier. The group never completely achieved a harmonizing of perspectives, but no one mentioned any authorship issues or complained that they were not fairly represented in the document. Problems resulting from authorship issues, which are described in several recent studies, did not surface during my observations of their process. In another sense, the group exhibited some traits that could characterize it as an integrated team. Paradoxically, the hierarchical 
model somewhat describes their effort as well because Electrophysicist was situated at the top of a hierarchy within the group. The members wrote text. He compiled the document, and he then sent it back to them for their review. He also made certain the document was submitted in a timely manner to DARPA. However, no one model or theory presented in the professional and technical communication literature fully describes the immune-building collaboration; however, elements of several models and theories can provide an appropriate lens for viewing this group and their writing process.

The group's final document represented a codification of expertise from each individual member. Each disciplinary perspective formed and shaped the text, and their final proposal represented, among other things, a codification of different disciplinary perspectives and voices. The notable exception was that Architect's objections to filtration did not result in an elimination of the filtration approach. Architect did not articulate an alternative solution, and the other group members ultimately decided that filters remained their best possible option. Regardless, multiple and differing disciplinary views created this discourse.

This group depended on strong leadership. Electrophysicist did not invalidate anyone else's opinion, although he came close with regard to Architect. Ultimately, effective leadership for the immune-building group became critical for managing "cortical depth of bench." An interdisciplinary group's leader should act as a unifying force, one who accommodates different disciplinary perspectives, and also one who recognizes the demands of time constraints and institutional guidelines. Without strong leadership, it becomes questionable as to whether or not interdisciplinary collaborators can succeed.

\section{Conclusion and CaLl for Further Research}

This piece describes a number of factors affecting interdisciplinary collaboration. Collaboration for this case study group relied considerably upon dialogue among the participants to build consensus, and subsequently, to write a document. By collaborating with others from very different disciplines, these experts were sometimes forced to think outside their own disciplinary boxes. It is difficult to argue that this situation was routine for collaborative writing, but as our technological communities and economies become increasingly global, these kinds of interdisciplinary collaborative writing situations will become more common because the complexity of global problems requires the talents of individuals from diverse backgrounds. This study offers the following conclusions:

First, for any interdisciplinary collaboration, a number of elements can focus the group. These elements include deadlines and time constraints. Members can exercise a degree of control over these factors to become a unified group and to increase focus on the writing project.

Second, as an interdisciplinary group, part of collaborating effectively requires that experts develop understandings of one another's discipline. This understanding means that each person begins to develop an understanding through language - even if that understanding is only superficial - to work effectively with others and to maximize the benefits of interdisciplinary collaboration.

Finally, disciplinary difference is a mixed blessing. The diversity of professionals working on a project can bring about novel and innovative approaches and solutions. However, disciplinary experts can also fail to extend their visions beyond their area of study and sometimes disregard or misunderstand another expert's point of view.

With regard to this case study group, the members articulated different perspectives on what the document should or should not contain. Architect could express his opinion that filters were not the best mechanism for the test bed, and Corporate Engineer could argue that concentration represented a more appropriate conceptual frame than dose. A question for this study, however, asks how these interdisciplinary members negotiate their differences. In some instances, disputes were easily settled; in the matter of concentration versus dose, for example, the other members agreed upon concentration as the concept for consideration. Because of the limitations of case study research and because of the difficulty generalizing from one case, Thompson's call for research into indeterminate zones of practice in collaboration should continue to be addressed.

\section{REFERENCES}

[1] K. Baake, Metaphor and Knowledge: The Rhetorical Challenges at a Postmodern Science Think Tank. Ann Arbor, MI: Univ. Michigan Press, 2000.

[2] J. Qin, F. W. Lancaster, and B. Allen, "Types and levels of collaboration in interdisciplinary research in the sciences," J. Amer. Soc. Inform. Sci., vol. 48, no. 10, pp. 893-916, 1997.

[3] J. S. Nelson, A. Megill, and A. McCloskey, Eds., The Rhetoric of the Human Sciences: Language and Argument in Scholarship and Public Affairs. Madison, WI: Univ. Wisconsin Press, 1987.

[4] S. P. MacDonald, Professional Academic Writing in the Humanities and Social Sciences. Carbondale, IL: Southern Illinois Univ. Press, 1994. 
[5] J. Henry, "The value added by technical communicators in collaborative writing situations," Tech. Commun., vol. 45, no. 2, pp. 207-220, 1998.

[6] P. Sullivan, "Collaboration between organizations: Contributions outsiders can make to negotiation and cooperation during composition," Tech. Commun., vol. 38, no. 4, pp. 485-492, 1991.

[7] C. H. Sides, "Collaboration in a hardware technical writing group: A real-world laboratory," Bulletin, vol. 1, no. 1, pp. 11-15, 1991.

[8] E. Malone, "Facilitating groups through selective participation," in Collaborative Writing in Industry: Investigations in Theory and Practice, M. M. Lay and W. M. Karis, Eds. Amityville, NY: Baywood, 1991, pp. 105-119.

[9] A. Lunsford and L. Ede, Singular Texts/Plural Authors: Perspectives on Collaborative Writing. Carbondale, IL: Southern Illinois Univ. Press, 1992.

[10] R. P. Rice and J. T. Huguley Jr., "Describing collaborative forms: A profile of the team-writing process," IEEE Trans. Profess. Commun., vol. 37, no. 3, pp. 163-170, 1994.

[11] R. Spilka, "Collaboration across multiple organizational cultures," Tech. Commun. Quart., vol. 2, no. 2, pp. 125-145, 1993.

[12] A. H. Duin and R. Archee, "Collaboration via e-mail and internet relay chat: Understanding time and technology,” Tech. Commun., vol. 43, no. 4, pp. 402-412, 1996.

[13] M. B. Debs, "Recent research on collaborative writing in industry," Tech. Commun., vol. 38, no. 4, pp. 476-484, 1991.

[14] M. J. Killingsworth and B. G. Jones, "Division of labor or integrated teams: A crux in the management of technical communication?," Tech. Commun., vol. 36, no. 3, pp. 210-221, 1989.

[15] B. Mirel, S. Feinberg, and L. Allmendinger, "Collaboration between writers and graphic designers in documentation projects," J. Bus. Tech. Commun., vol. 9, no. 3, pp. 259-288, 1995.

[16] M. Schrage, No More Teams!: Mastering the Dynamics of Creative Collaboration. New York: Doubleday, 1995.

[17] L. Rehling, "Is it theirs, mine, or ours?' Ownership, collaboration, and cultures," IEEE Trans. Profess. Commun., vol. 37, no. 1, pp. 42-49, 1994.

[18] B. Couture and J. Rymer, "Discourse interaction between writer and supervisor: A primary collaboration in workplace writing," in Collaborative Writing in Industry: Investigations in Theory and Practice, M. M. Lay and W. M. Karis, Eds. Amityville, NY: Baywood, 1991, pp. 87-108.

[19] L. Sherry and K. M. Myers, "The dynamics of collaborative design," IEEE Trans. Profess. Commun., vol. 41, no. 2, pp. 123-139, 1998.

[20] D. I. Ballard and D. R. Seibold, "Time orientation and temporal variation across work groups: Implications for group and organizational communication," Western J. Commun., vol. 64, no. 2, pp. 218-242, 2000.

[21] G. A. Cross, Collaboration and Conflict: A Contextual Exploration of Group Writing and Positive Emphasis. Cresskill, NJ: Hampton Press, 1994.

[22] S. K. Bishop, "Cross-functional project teams in functionally aligned organizations,” Proj. Manage. J., vol. 30, no. 3, pp. 6-12, 1999.

[23] G. Tesar, "Product decisions and cross-functional teams: Implications for engineers," Midwest Eng., vol. 51, no. 1, pp. 6-8, 1999.

[24] T. Marchwinski and K. Mandziuk, "The technical communicator's role in initiating cross-functional teams," Tech. Commun., vol. 47, no. 1, pp. 67-76, 2000.

[25] C. Wick, "Knowledge management and leadership opportunities for technical communicators," Tech. Commun., vol. 47 , no. 4 , pp. 515-529, 2000.

[26] I. Thompson, "Collaboration in technical communication: A qualitative content analysis of journal articles, 1990-1999,” IEEE Trans. Profess. Commun., vol. 44, no. 2, pp. 161-173, 2001.

[27] L. A. Chiodo, private communication, Oct. 25, 2000.

[28] G. C. Bowker, "Biodiversity datadiversity," Social Studies Sci., vol. 30, no. 4, pp. 643-668, 2001.

[29] Y. Engeström and R. Miettinen, "Introduction,” in Perspectives on Activity Theory, Y. Engeström, R. Miettinen, and R. L. Punamäki, Eds. Cambridge, UK: Cambridge Univ. Press, 1999, pp. 1-18.

[30] S. Eggins and J. R. Martin, "Genres and registers of discourse," in Discourse as Structure and Process, T. A. Van Dijk, Ed. London, UK: Sage, 1997, pp. 230-256.

[31] E. Duncker, "Symbolic communication in multidisciplinary cooperations," Sci., Technol., Human Values, vol. 26, no. 3, pp. 349-386, 2001.

[32] J. Swales, Genre Analysis: English in Academic Settings, Cambridge, UK: Cambridge Univ. Press, 1994.

[33] G. Myers, Writing Biology: Texts in the Social Construction of Scientific Knowledge. Madison, WI: Univ. Wisconsin Press, 1990.

[34] G. A. Cross, Forming the Collective Mind: A Contextual Exploration of Large-Scale Collaborative Writing in Industry. Cresskill, NJ: Hampton Press, 2001.

[35] K. E. Weick and K. H. Roberts, "Collective mind in organizations: Heedful interrelating on flight decks," Admin. Sci. Quart., vol. 38, no. 3, pp. 357-381, 1993.

[36] H. W. Ko, private communication, Dec. 5, 2000.

J ohn C. Gooch earned a Ph.D. in technical communication and rhetoric from Texas Tech University in 2002. Gooch has taught in both four-year and two-year institutions of higher learning, and has also worked as a professional communicator for public agencies and private industry. He currently holds a faculty position in the Department of Communication at the University of Texas at Dallas, where he teaches courses in technical and scientific communication and also rhetoric. 